\title{
The Yield and Safety of Screening Colonoscopy in Patients Evaluated for Liver Transplantation
}

\author{
Rosalie C. Oey (D) ${ }^{1 *}$ Laurelle van Tilburg, ${ }^{1 *}$ Nicole S. Erler, ${ }^{2}$ Herold J. Metselaar, ${ }^{1}$ Manon C.W. Spaander, ${ }^{1}$ Henk R. van Buuren, ${ }^{1}$ \\ and Robert A. de Man ${ }^{1}$
}

Colorectal cancer (CRC) screening with colonoscopy is commonly used in patients who are candidates for liver transplantation. We initiated this study to define the risk-benefit ratio of performing screening colonoscopy in this population. A retrospective observational study of all consecutive patients undergoing colonoscopy during pre-liver transplantation screening between 2004 and 2017 was conducted. Endoscopic and pathological findings and clinical events potentially related to the colonoscopy in the 30 days after the procedure were registered and compared with a 30-day inpatient control time frame. A total of 858 colonoscopies were performed in 808 patients $(65 \%$ male; median age, 55 years [interquartile range (IQR), 47-62]; median model for end-stage liver disease (MELD) score, 15 [IQR, 11-18]). CRC was found in 2 patients (0.2\%), and advanced adenomas were found in 44 patients (5.4\%). The only independent risk factor for an advanced neoplasm was age (odds ratio, 1.072 per year; $95 \%$ confidence interval, 1.031-1.115; $P<0.001$ ). During the 30-day postprocedure period, 178 clinical events occurred in 128 patients compared with 101 clinical events in 72 patients in the control time frames $(P<0.001)$. After colonoscopy, there was a significantly increased risk for renal failure $(P=0.001)$ and gastrointestinal $(\mathrm{GI})$ bleeding $(P=0.023)$. Presence of ascites and MELD score were identified as independent risk factors for acute renal failure and GI bleeding. During the study observation period, $53.5 \%$ of the screened population actually underwent liver transplantation. Conclusion: CRC screening in pre-liver transplantation patients is associated with a relatively low prevalence of CRC and an increased risk of postcolonoscopy complications such as acute renal failure and GI bleeding, especially in patients with advanced liver disease. Because the risk-benefit ratio of standard performance of a screening colonoscopy in this population appears questionable, alternative screening strategies should be considered. (Hepatology 2019;69:2598-2607).

olonoscopy is commonly performed as part of the standard screening for neoplastic lesions in patients who are candidates for liver transplantation, although international guidelines do not clearly state in which patients it should be mandatorily performed or might be omitted. ${ }^{(1-3)}$

The prevalence of colorectal cancer (CRC) in liver transplantation candidates has not been well defined.

Abbreviations: CI, confidence interval; CRC, colorectal cancer; FIT, fecal immunochemical test; GI, gastrointestinal; HCC, hepatocellular carcinoma; HE, hepatic encephalopathy; IBD, inflammatory bowel disease; INR, international normalized ratio; IQR, interquartile range; $M E L D$, model for end-stage liver disease; $O R$, odds ratio; $P S C$, primary sclerosing cholangitis; SBP, spontaneous bacterial peritonitis; SD, standard deviation; SSA/P, sessile serrated adenomalpolyp; TSA, traditional serrated adenoma.

Received September 19, 2018; accepted February 10, 2019.

Additional Supporting Information may be found at onlinelibrary.wiley.com/doi/10.1002/hep.30562/suppinfo.

*These authors contributed equally to this work.

Supported by the Foundation for Liver and Gastrointestinal Research, Rotterdam.

(C) 2019 The Authors. HEPATOLOGY published by Wiley Periodicals, Inc., on behalf of American Association for the Study of Liver Diseases. This is an open access article under the terms of the Creative Commons Attribution-NonCommercial License, which permits use, distribution and reproduction in any medium, provided the original work is properly cited and is not used for commercial purposes.

View this article online at wileyonlinelibrary.com.

DOI 10.1002/hep.30562

Potential conflict of interest: Prof. de Man is on the speakers' bureau for Gilead. He received grants from Norgine and AbbVie. Prof. Metselaar advises Astellas and Novartis. 
Several studies have reported that the prevalence of premalignant colon lesions (i.e., advanced adenomas) in this patient population varies from $5.8 \%$ to $13.9 \%{ }^{(4-8)}$ Removal of these precursor lesions is recommended, considering the potentially accelerated rate of progression to CRC during long-term immunosuppressive therapy after transplantation. ${ }^{(9)}$

In addition, few quantitative data are available pertaining to the safety of colonoscopy in this population. Several case series have suggested that patients with end-stage liver disease undergoing colonoscopy are at increased risk for hemorrhage and perforation after polypectomy. ${ }^{(10,11)}$ Other reported complications include bacteremia, peritonitis, and renal failure. ${ }^{(12-19)}$

The aim of the present study was to assess the yield and safety of screening colonoscopy in a large consecutive cohort of patients who underwent evaluation for liver transplantation by investigating the prevalence and predictive factors for CRC and advanced adenomas and the incidence and predisposing factors for postprocedural complications.

\section{Patients and Methods}

\section{STUDY DESIGN AND PATIENTS}

All consecutive patients undergoing colonoscopy during pre-liver transplantation screening from January 1, 2004, to May 1, 2017, in the Erasmus Medical Center, Rotterdam, the Netherlands, were retrospectively included. The study protocol conforms to the ethical guidelines of the 1975 Declaration of Helsinki as reflected in approval by the institution's human research committee on January 23, 2017. Written informed consent was not necessary, considering the nature of the study.

\section{COLONOSCOPY PROCEDURE}

Bowel preparation was achieved using polyethylene electrolyte glycol (PEG) solutions. Sedation, using midazolam and/or fentanyl, was performed at the discretion of the patients' preference and physicians' judgement. Endoscopic reports were retrieved from the automated EndoALPHA reporting system (ENDOBASE; Olympus Winter \& Ibe, Hamburg, Germany). Specimens of resected colon tissue were processed and reviewed by specialized gastrointestinal (GI) pathologists using standard histologic methods.

\section{DATA COLLECTION}

Clinical patient characteristics at the time of colonoscopy, including sex, age, cause and severity of liver disease, presence of hepatocellular carcinoma (HCC), presentence of ascites (graded as none, diuretic-responsive, and refractory), presence of hepatic encephalopathy (HE) (graded according to the West-Haven criteria), and laboratory values (creatinine, albumin, bilirubin, and international normalized ratio [INR]), were collected from electronic patient records. Data of the colonoscopy procedure, including use of premedication, adequacy of bowel preparation, cecal intubation rate, tumor size, morphologic and histopathologic characteristics, polyps, and other endoscopic findings (e.g., inflammatory bowel disease $[\mathrm{IBD}]$, rectal varices, and portal enteropathy), were recorded. In the context of this study, patients were followed until 1 year after liver transplantation, until the date of death when not undergoing transplant, or until the end of the study observation period (August 1, 2018) when they were still on the waiting list.

\section{ARTICLE INFORMATION:}

From the ${ }^{1}$ Department of Gastroenterology and Hepatology, Erasmus Medical Center University Hospital, Rotterdam, the Netherlands; ${ }^{2}$ Department of Biostatistics, Erasmus Medical Center University Hospital, Rotterdam, the Netherlands.

\section{ADDRESS CORRESPONDENCE AND REPRINT REQUESTS TO:}

Rosalie C. Oey, M.D.

Department of Gastroenterology and Hepatology

Erasmus MC University Hospital

Room Na-606
P.O. Box 2040

3000 CA Rotterdam, the Netherlands

E-mail: r.oey@erasmusmc.nl

Tel.: +316-12894554 


\section{COMPLICATIONS}

All clinical events potentially related to the colonoscopy were registered in the 30-day period after the procedure. To assess colonoscopy-associated risk in comparison with the general risk in this particular population, relevant clinical events were also registered in the 30 -day period preceding the procedure when this was performed in even years (e.g., 2004, 2006, and so on) and between day 31 and day 60 after the procedure when this was performed in uneven years (Fig. 1). Patients who received a liver transplantation or who died during the control time frame were not taken into account with respect to the assessment of complications. The following events were considered to be potentially related to colonoscopy: postpolypectomy hemorrhage, colon perforation, acute renal failure, GI bleeding, new onset or worsening of ascites and $\mathrm{HE}$, bacterial infections (including bacteremia, fever of unknown origin, spontaneous bacterial peritonitis [SBP], and respiratory, urogenital, and other infections), cardiopulmonary events (including new-onset arrhythmias, myocardial infarction, congestive heart failure, aspiration pneumonia, and respiratory insufficiency), and significant rise in serum bilirubin.

\section{DEFINITIONS}

Liver disease severity scores were calculated, and patients were classified according to Child-Pugh class. ${ }^{(20)}$ The model for end-stage liver disease (MELD) score was calculated with the following formula:
$0.957 \times \log ($ creatinine in milligrams per deciliter $)+$ $0.378 \times \log ($ bilirubin in milligrams per deciliter $)+$ $1.120 \times \log ($ INR $)+0.643 .{ }^{(21,22)}$ The adequacy of bowel preparation was classified as inadequate, poor, fair, good, or excellent using the Aronchick bowel preparation scale. ${ }^{(23,24)}$ Cecal intubation was defined as complete visualization and intubation of the cecum, confirmed by the visual landmarks of the ileocecal valve and triradiate cecal fold. ${ }^{(25)}$ Patients with an inadequate or poor bowel preparation were excluded from cecal intubation rate calculations. Colon tissue specimens were classified as normal colon tissue, hyperplastic polyps, inflammatory polyps, nonadvanced adenomas, advanced adenomas, or CRC. ${ }^{(26)}$ Nonadvanced adenoma was defined as all tubular adenoma and serrated nonadvanced adenoma. ${ }^{(26)}$ Sessile serrated adenoma/polyp (SSA/P) was defined as predominantly architectural distortion with irregular dilated crypts that often have an $L$ or $T$ shape. ${ }^{(27)}$ Traditional serrated adenoma (TSA) was defined as protuberant or pedunculated grown pattern with distorted villiform configurations, with columnar cells having abundant eosinophilic cytoplasm or centrally located elongated nuclei. ${ }^{(27)}$ Advanced adenomas were defined as adenomas $\geq 10 \mathrm{~mm}$, adenomas with high-grade dysplasia, or adenomas with a villous component of at least $25 \%$. $^{(26,28)}$ Cancers were staged according to the TNM staging system, described in the seventh edition of the American Joint Committee on Cancer staging manual. ${ }^{(29)}$ Advanced neoplasia was defined as advanced adenoma and/or CRC.

Acute renal failure was defined as a serum creatinine increase by $50 \%$ or more within 7 days or an increase

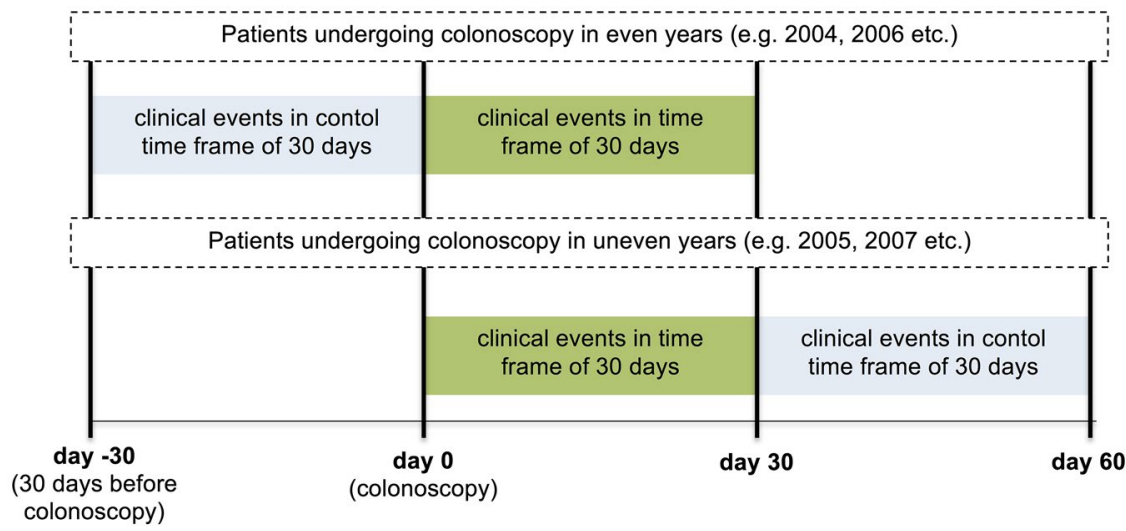

FIG. 1. Schematic view of the chosen control time frames in this study. 
of $0.3 \mathrm{mg} / \mathrm{dL}(26.5 \mu \mathrm{mol} / \mathrm{L})$ within 2 days. ${ }^{(30,31)} \mathrm{GI}$ bleeding was defined as all forms of variceal bleeding in the upper or lower GI tract (thus excluding bleeding form a polypectomy site). ${ }^{(32)} \mathrm{New}$-onset or worsening $\mathrm{HE}$ was defined as newly diagnosed $\mathrm{HE}$ or an increase of neurocognitive changes according to the West-Haven clinical criteria. ${ }^{(33,34)} \mathrm{New}$-onset ascites or worsening ascites were defined as a sudden increase of ascites and confirmation by ultrasound or fluid drainage by paracentesis. Bacterial infections were classified using Centers for Disease Control and Prevention criteria. ${ }^{(35,36)}$ Fever of unknown origin was defined as a prolonged febrile illness that persists without diagnosis after careful initial assessment. ${ }^{(37)}$ $\mathrm{SBP}$ was defined as a polymorphonuclear cell count in ascites $\geq 250 / \mu \mathrm{L}$ without a surgically treatable abdominal source of infection. ${ }^{(38)}$ A bilirubin increase was defined as an increase of at least $5 \mathrm{mg} / \mathrm{dL}(85 \mu \mathrm{mol} / \mathrm{L})$ within 2 days.

\section{STATISTICAL ANALYSIS}

Continuous variables were reported as the mean with standard deviation (SD) after visual confirmation of approximate normality and were compared using the Student $t$ test. Continuous variables with a nonnormal distribution were reported as the median with interquartile range (IQR) expressed as the twentyfifth to the seventy-fifth percentile. Categorical variables were reported as count with proportion and compared using the chi-square test. A two-sided $P$ value $<0.05$ was considered significant.

Multivariable logistic regression, carried out to identify risk factors for cecal intubation failure, included the following candidate predictor variables: sex, age, MELD score, ascites, HE, and sedation medication during colonoscopy. Multivariable logistic regression, carried out to identify risk factors for an advanced neoplasm, included the following candidate predictor variables: sex, age, liver disease cause, HCC, MELD score, and CRC screening (i.e., colonoscopy, fecal occult blood test [FOBT]/ fecal immunochemical test [FIT], computed tomography [CT] colonography, or barium enema examination) in the prior 5 years. Multivariable analyses for the logistic regression models were employed using the backward stepwise selection method with removal testing based on the significance of the likelihood-ratio statistic.
Kaplan-Meier analysis was used to estimate 1-year and 2-year survival rates after liver transplantation.

All statistical analyses were performed using IBM SPSS Statistics for Windows, version 24.0.0.1 (IBM Corp., Armonk, NY).

\section{Results}

\section{PATIENT CHARACTERISTICS}

From January 1, 2004, to May 1, 2017, 1,145 patients underwent pre-liver transplantation screening in the Erasmus MC, Rotterdam, the Netherlands. A total of 337 patients were not included in the study, mainly because colonoscopy was performed in a referring hospital ( $\mathrm{n}=90)$, patients were listed with highly urgent priority $(n=74)$, or the screening was prematurely terminated because of clinical deterioration of the patient condition $(\mathrm{n}=41)$. The remaining 808 patients were included for the present analysis (Fig. 2). The study cohort included 524 men and 284 women with a median age 55 years (IQR, 47-62) at the time of colonoscopy (Table 1). The most frequent reason for pre-liver transplantation screening was alcoholic liver disease (22.9\%), followed by viral hepatitis (21.4\%) and primary sclerosing cholangitis (PSC) (17.6\%) (Table 1). The prevalence of IBD in patients diagnosed with PSC was 59.9\% (85/142 patients). HCC was present in 223 patients (27.6\%). The median MELD score was 15 (IQR, 11-18; range, 6-40), $24.5 \%$ of patients had diuretic-responsive ascites, $16.6 \%$ had refractory ascites, and 97 (12\%) patients had $\mathrm{HE}$ at the time of colonoscopy. Approximately 20\% of patients used at least one antibiotic agent during colonoscopy. One-fifth of patients received colorectal screening in the prior 5 years by colonoscopy; no cases were identified of patients undergoing colonoscopy after a positive screening with FOBT/FIT, CT colonography, or barium enema examination (Table 1).

\section{COLONOSCOPY PROCEDURE}

A total of 864 colonoscopies were performed in 808 patients. Bowel preparation adequacy was available in 663 patients and was scored as excellent in $7.1 \%$, good in $54.6 \%$, fair in $16.1 \%$, poor in $3.3 \%$, and inadequate in $1 \%$. Cecal intubation rate of the index colonoscopy was $96.7 \%$. Cecal intubation failed because of loop formation in 15 patients and because 


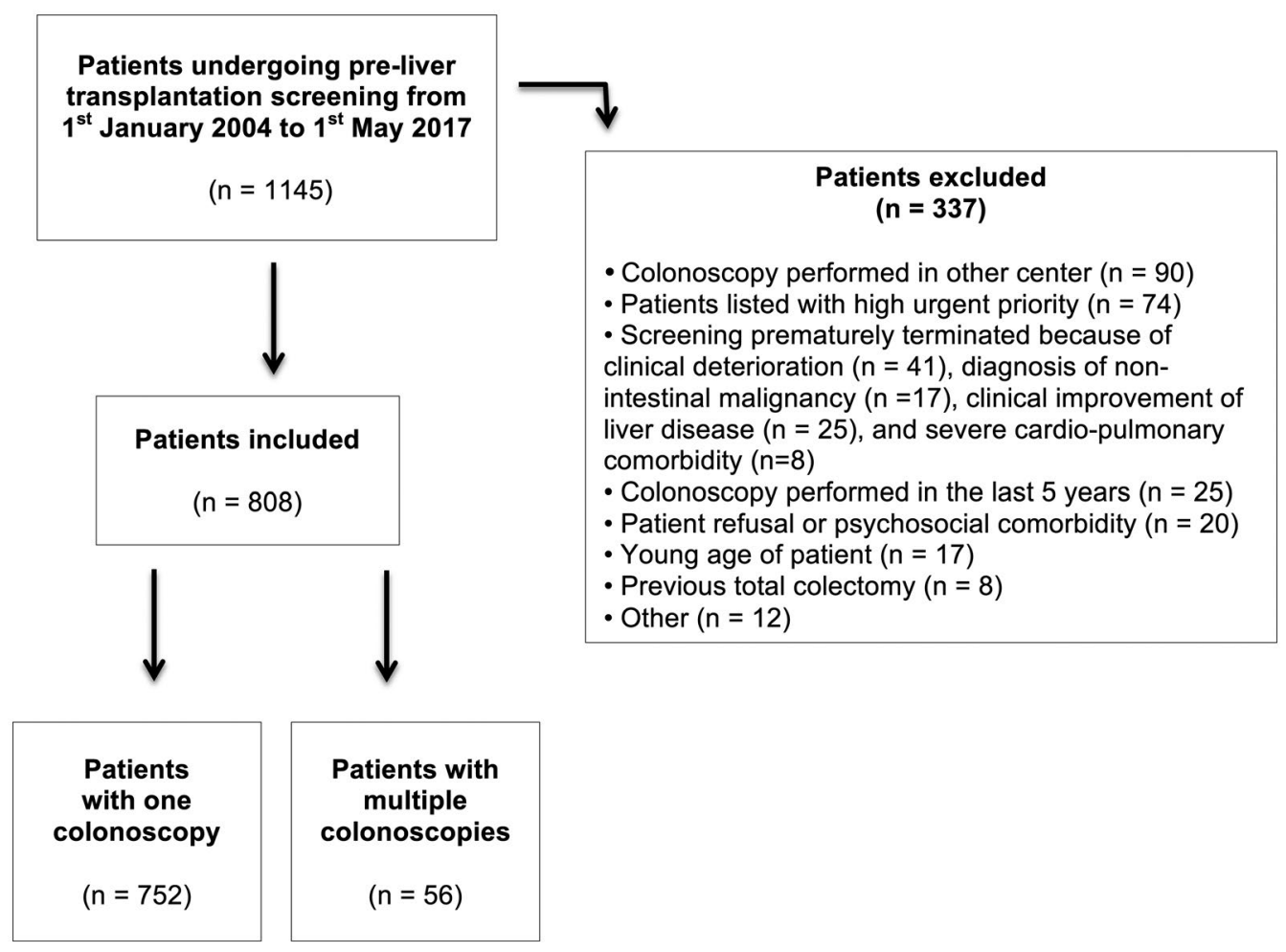

FIG. 2. Flow chart of study inclusion.

of abortion due to patient discomfort/abdominal pain in 12 patients. Multivariable logistic regression, carried out for risk factors for cecal intubation failure, identified MELD score (odds ratio [OR], 1.090 per point; 95\% confidence interval [CI], 1.015-1.170; $P=0.018)$ as an independent risk factor.

In total, 56 repeat colonoscopies were performed because of several reasons: poor bowel preparation ( $\mathrm{n}$ = 13), initial cecal intubation failure $(\mathrm{n}=25)$, anticoagulation status contraindicated polypectomy $(n=9)$, patients needed a repeat colonoscopy after a period of 3 years on the liver transplantation waiting list or for liver retransplantation $(n=6)$, or additional polypectomy or surveillance after polypectomy $(n=3)$. In 6 patients with initial cecal intubation failure and in 5 patients with poor bowel preparation, subsequent colonoscopy was postponed until after the transplantation.

In this cohort, 799/864 (92.4\%) colonoscopies were performed under conscious sedation using intravenous midazolam and fentanyl. Sixty-five procedures were performed using fentanyl $(n=25)$, remifentanil $(n=7)$, or without any premedication $(n=33)$. Patients did not receive standard periprocedural antibiotic prophylaxis.

\section{DIAGNOSTIC YIELD}

In total, 625 polypectomies were performed during colonoscopy, with an average of 2.3 polypectomies $( \pm 1.3)$ per patient. At colonoscopy, advanced neoplasia was found in $46(5.6 \%)$ patients: advanced adenoma in $44(5.4 \%)$ and $\mathrm{CRC}$ in $2(0.2 \%)$. Nonadvanced adenoma was found in 151 patients (18.7\%), including SSA/P or TSA in 13 patients (1.6\%), hyperplastic polyps in 130 patients (16.1\%), and inflammatory polyps in 3 patients $(0.4 \%)$ (Table 2$)$.

In 58 of the remaining 465 patients, a lesion was macroscopically present, but polypectomy was not attempted because of impaired coagulation and/or a macroscopically benign character $(n=41)$ or because histopathologic evaluation was not possible as a result of loss or insufficient yield of tissue ( $n=17)$. At a subsequent colonoscopy, advanced adenoma was diagnosed in 3 of 58 cases, and CRC was diagnosed in none.

The only independent risk factor for advanced neoplasia was age (odds ratio, 1.072 per year; 95\% CI, 1.031-1.115; $P<0.001)$. Advanced neoplasia was diagnosed in $5.6 \%$ of the patients aged 60 years or 
TABLE 1. Patient Baseline Clinical Characteristics at the Time of Screening Colonoscopy

\begin{tabular}{|c|c|}
\hline & Patients $(n=808)$ \\
\hline Male sex, n (\%) & $524(64.9)$ \\
\hline Age in years, median (IQR) & $55(47-62)$ \\
\hline \multicolumn{2}{|l|}{ Cause of liver disease, n (\%) } \\
\hline Alcoholic liver disease & $185(22.9)$ \\
\hline Viral hepatitis & $173(21.4)$ \\
\hline PSC & $142(17.6)$ \\
\hline PBC/autoimmune hepatitis & $65(8.0)$ \\
\hline Cryptogenic liver cirrhosis & $58(7.2)$ \\
\hline NASH & $41(5.1)$ \\
\hline Other & $144(17.8)$ \\
\hline $\mathrm{HCC}, \mathrm{n}(\%)$ & $223(27.6)$ \\
\hline \multicolumn{2}{|l|}{ Blood serum parameters } \\
\hline Creatinin $(\mu \mathrm{mol} / \mathrm{L})$, median $(\mathrm{IQR})$ & $71(59-90)$ \\
\hline Albumin (g/L), mean (SD) & $33( \pm 7)$ \\
\hline Bilirubin $(\mu \mathrm{mol} / \mathrm{L})$, mean $(\mathrm{SD})$ & $87( \pm 126)$ \\
\hline INR, mean (SD) & $1.4( \pm 0.4)$ \\
\hline \multicolumn{2}{|l|}{ Liver disease severity scores } \\
\hline MELD score, median (IQR) & $15(11-18)$ \\
\hline \multicolumn{2}{|l|}{ Child-Pugh class, n (\%) } \\
\hline$A$ & $473(58.5)$ \\
\hline B & $294(36.4)$ \\
\hline C & $41(5.1)$ \\
\hline \multicolumn{2}{|l|}{ Ascites, n (\%) } \\
\hline None & $476(58.9)$ \\
\hline Diuretic-responsive & $198(24.5)$ \\
\hline Refractory & $134(16.6)$ \\
\hline \multicolumn{2}{|l|}{$H E, n(\%)$} \\
\hline None & $711(88.0)$ \\
\hline West-Haven grade 1-2 & $71(8.8)$ \\
\hline West-Haven grade 3-4 & $26(3.2)$ \\
\hline Antibiotic use, ${ }^{*} \mathrm{n}(\%)$ & $162(20.0)$ \\
\hline Norfloxacin & $82(10.1)$ \\
\hline Rifaximin & $48(5.9)$ \\
\hline Rifamipicin & $9(1.1)$ \\
\hline Ciprofloxacin & $17(2.1)$ \\
\hline Amoxicilin and clavulanic acid & $5(0.6)$ \\
\hline Other & $12(1.5)$ \\
\hline $\begin{array}{l}\text { Colorectal screening in the prior } 5 \\
\text { years, } \mathrm{n}(\%)\end{array}$ & $193(23.9)$ \\
\hline
\end{tabular}

*11 patients used multiple antibiotic agents.

Abbreviations: NASH, nonalcoholic steatohepatitis; PBC, primary biliary cirrhosis.

older, in $5.4 \%$ of the patients aged 50-59 years, and in $1.8 \%$ of the patients aged $40-49$ years; no advanced neoplasm was diagnosed below the age of 40 years (Fig. 3). The 2 patients with CRC were a 62-year-old female with a T2N0M0 rectal adenocarcinoma and a
TABLE 2. Findings at Colonoscopy

Patients $(n=808)$

\begin{tabular}{|c|c|}
\hline \multicolumn{2}{|l|}{ Diagnostic yield, ${ }^{*} \mathrm{n}(\%)$} \\
\hline CRC & $2(0.2)$ \\
\hline Advanced adenoma & $44(5.4)$ \\
\hline$\geq 10 \mathrm{~mm}$ & 17 \\
\hline$\geq 25 \%$ villous & 9 \\
\hline high-grade dysplasia & 4 \\
\hline$\geq 10 \mathrm{~mm}+$ high-grade dysplasia & 3 \\
\hline$\geq 10 \mathrm{~mm}+\geq 25 \%$ villous & 8 \\
\hline $\begin{array}{l}\geq 25 \% \text { villous + high-grade } \\
\text { dysplasia }\end{array}$ & 1 \\
\hline $\begin{array}{l}\geq 10 \mathrm{~mm}+\geq 25 \% \text { villous + } \\
\text { high-grade dysplasia }\end{array}$ & 2 \\
\hline Nonadvanced adenoma & $164(20.3)$ \\
\hline SSA/P or TSA & 13 \\
\hline Hyperplastic polyp & $130(16.1)$ \\
\hline Inflammatory polyp & $3(0.4)$ \\
\hline No lesions & $465(57.6)$ \\
\hline \multicolumn{2}{|l|}{ Other colon pathologies, ${ }^{\dagger} \mathrm{n}(\%)$} \\
\hline IBD & $92(11.4)$ \\
\hline Rectal varices & $72(8.9)$ \\
\hline Angiodysplasia & $61(7.5)$ \\
\hline Portal hypertension & $58(7.2)$ \\
\hline Diverticulosis & $57(7.1)$ \\
\hline Hemorrhoids & $42(5.2)$ \\
\hline \multicolumn{2}{|c|}{$\begin{array}{l}\text { *According to the most advanced lesion. } \\
{ }^{\dagger} \text { Patients could have multiple other pathologies. }\end{array}$} \\
\hline \multicolumn{2}{|c|}{$\begin{array}{l}\text { 64-year-old female with a T2N0M0 adenocarcinoma } \\
\text { of the sigmoid colon. }\end{array}$} \\
\hline
\end{tabular}

In 294 patients (36.4\%), other colon pathologies were reported (Table 2). There were no cases of newly diagnosed IBD.

\section{COMPLICATIONS AFTER COLONOSCOPY}

During the 30-day period after colonoscopy, 178 clinical events occurred in 128 (14.9\%) patients compared with 101 clinical events in $72(8.6 \%)$ patients in the control time frames $(P<0.001)$ (Table 3$)$.

After colonoscopy, there was a significantly increased risk for acute renal failure (33 vs. $10 ; P=0.001$ ). Patients with acute renal failure had an average creatinine rise of $66 \mu \mathrm{mol} / \mathrm{L}$; 35 were treated with volume expansion, albumin, and/or vasopressors, and 8 were 


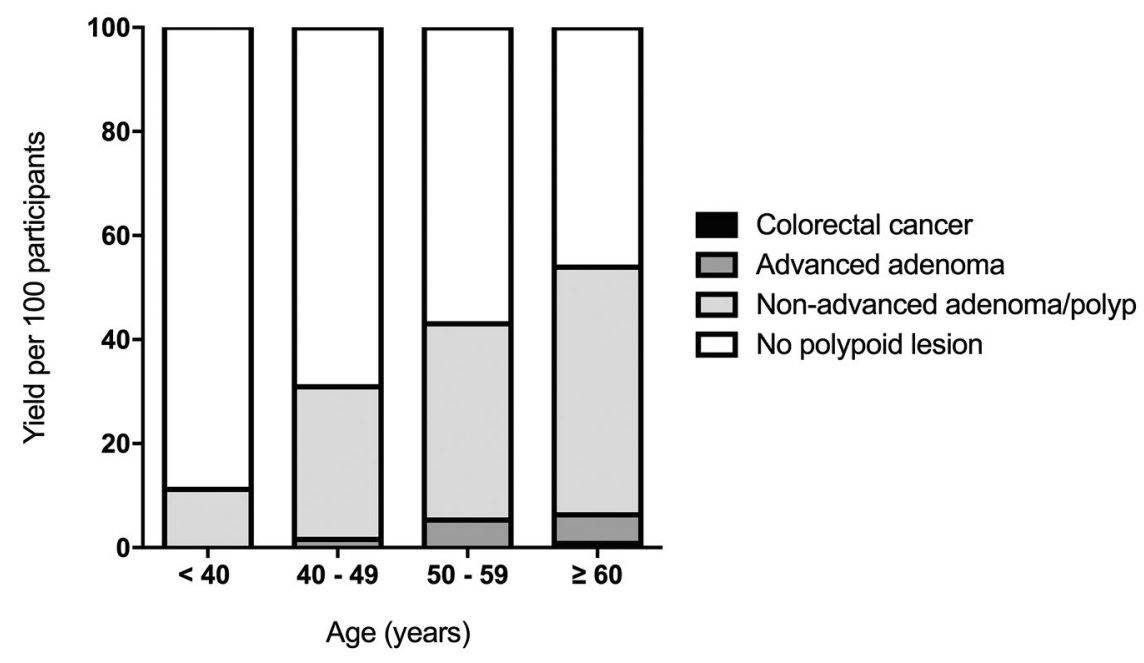

FIG. 3. Most advanced lesion per participant found during colonoscopy.

TABLE 3. Frequency of Complications in Patients Undergoing Screening Colonoscopy

\begin{tabular}{lccc} 
& $\begin{array}{c}\text { Complications During 30 Days After } \\
\text { Colonoscopy }(\mathrm{n}=858)\end{array}$ & $\begin{array}{c}\text { Complications During 30-Day Control } \\
\text { Time Frame }(\mathrm{n}=835)\end{array}$ & PValue \\
\hline Acute renal failure, $\mathrm{n}(\%)$ & $33(3.8)$ & $10(1.2)$ & 0.001 \\
Gastrointestinal bleed, $\mathrm{n}(\%)$ & $25(2.9)$ & $11(1.3)$ & 0.023 \\
Bacterial infection, $\mathrm{n}(\%)$ & $54(6.3)$ & $37(4.4)$ & 0.089 \\
SBP & 18 & 17 & - \\
Fever of unknown origin & 15 & 6 & - \\
Bloodstream infection & 12 & 3 & - \\
Respiratory infection & 4 & - & - \\
Gl infection & 4 & 7 & - \\
Urogenital infection & 3 & 3 & 0.109 \\
Other & 0 & 1 & 0.058 \\
HE, $n$ (\%) & $47(5.5)$ & $32(3.8)$ & - \\
Pulmonary complications, $n(\%)$ & $10(1.2)$ & $3(0.4)$ & - \\
(Aspiration) pneumonia & 3 & - & 0.391 \\
Respiratory insufficiency & 7 & 3 & - \\
Cardiac complications, $n$ (\%) & $7(0.8)$ & $4(0.5)$ & - \\
New-onset arrhythmia & 5 & 1 & - \\
Congestive heart failure & 2 & 2 & 0.169 \\
Myocardial ischemia & - & 1 & 0.324 \\
Ascites (new-onset or worsening), $n$ (\%) & $1(0.1)$ & $4(0.5)$ & - \\
Bilirubin increase, $n$ (\%) & $1(0.1)$ & &
\end{tabular}

Note: Bold indicates a $P$ value below 0.05 .

treated with dialysis. The presence of ascites (diuretic-responsive ascites OR, 1.199; 95\% CI, 0.356-4.038; refractory ascites OR, 5.384; 95\% CI, 1.935-14.978; $P=0.001)$ and high MELD score (OR, 1.265 per point; 95\% CI, 1.180-1.356; $P<0.001)$ were independent risk factors for postcolonoscopy renal failure.
The risk for GI bleeding not originating from polypectomy sites was also significantly elevated after colonoscopy (25 vs. 11; $P=0.023$ ). MELD score (OR, 1.127 per point; $95 \%$ CI, 1.061-1.197; $P<0.001$ ) was found to be an independent risk factor for postcolonoscopy GI bleeding. 
Furthermore, there was a nonsignificant increase in bacterial infections (54 vs. 37 cases; $P=0.089$ ), HE (47 vs. 32 cases; $P=0.109$ ), pulmonary complications (10 vs. 3 cases; $P=0.058$ ), and cardiac complications ( 7 vs. 4 cases; $P=0.391$ ) in the postcolonoscopy and control time frames, respectively (Table 3).

Postpolypectomy hemorrhage occurred in 2 patients; both could be endoscopically managed. In 1 patient, colon perforation occurred after polypectomy, which was successfully treated conservatively.

Because the study duration was 13.5 years, the impact of the time of screening was measured on the detection of advanced adenomas and complication occurrence. There were no statistically significant differences regarding the time of screening on these outcome measures (Supporting Fig. S1).

\section{CLINICAL COURSE}

The median follow-up time was 285 days (IQR, 106-636). In this cohort, 260 patients (32.2\%) died, 432 patients $(53.3 \%)$ received a liver transplant, and 116 patients (14.4\%) were waiting for a liver transplant at the end of the observation period. The 1-year survival rate after liver transplantation was $91 \%$, and the 2-year survival rate was $88 \%$.

\section{Discussion}

In this study, we assessed the diagnostic yield and safety of performing a screening colonoscopy in patients evaluated for liver transplantation. We found that $\mathrm{CRC}$ was diagnosed in $0.2 \%$ of the population and that advanced adenoma was diagnosed in 5.4\%. Age was the only significant predictive factor for advanced neoplasia. Furthermore, colonoscopy with standard PEG bowel preparation was associated with a significantly increased risk for renal failure and nonpolypectomy GI bleeding, especially in patients with the most severe liver disease.

A key finding of the present study is the relatively low prevalence of CRC in this patient population. These results are consistent with those of comparable studies that did not find any case of CRC in patients undergoing pretransplantation evaluation. ${ }^{(6,8,39)}$ The $5.4 \%$ prevalence of advanced adenomas in our study was comparable to that reported by Weismuller et al. (prevalence, 5.8\%; 243 patients with a mean age of 53 years) but differs markedly from the $13.9 \%$ prevalence (567 patients; median age of 54 years) reported by Jeschek et al. ${ }^{(6,8)}$ These diverging results may be related to differences in study methodology, as the latter study results were not based on the actual diagnosed rate of advanced adenomas but were rather based on a statistical adjustment of this number, assuming the same rate of advanced adenomas among resected and nonresected polyps. ${ }^{(8)}$ The results of large cohort studies assessing the prevalence rate of advanced neoplasms in unselected healthy subjects, although of slightly older age, are in line with those in our study. Imperiale et al. reported a CRC rate of $0.6 \%$ and an advanced adenoma rate of $5.6 \%$ in 1,994 patients with a mean age of 60 years, and Stoop et al. found a rate of $0.5 \%$ and $8.2 \%$, respectively, in 1,276 patients with a mean age of 61 years. ${ }^{(40,41)}$

Another important finding is that $53.5 \%$ of the population undergoing screening actually underwent liver transplantation. Although $14.4 \%$ are still waiting for a liver transplant, a substantial proportion of patients have died on the waiting list or were not placed on the waiting list because of contraindications for liver transplantation. ${ }^{(42)}$ Moreover, 9\% of the 432 patients who underwent transplantation died within 1 year, and an additional 3\% died in the second year after transplantation. Thus, the number of patients who could theoretically benefit from screening colonoscopy is further decreased by the operative and postoperative mortality.

Our results indicate that colonoscopy increases the risk for complications such as acute renal failure and GI bleeding. We hypothesize that this may be related to bowel preparation with an inherent substantial fluid load that may induce unwanted circulatory alterations and fluid shifts. Indeed, water retention in patients with a preexistent hyperdynamic circulation, increasing the portal venous pressure, has been reported in patients undergoing bowel preparation with decompensated liver disease, congestive heart failure, and chronic renal insufficiency. ${ }^{(13,43)}$ Our study result that MELD score is the most important predictive factor for these complications after colonoscopy supports this theory.

The cecal intubation rate of $96.7 \%$ in our study is fairly similar to the rate of $83 \%-96 \%$ found in other cohorts of patients evaluated for liver transplantation. ${ }^{(6,39)}$ Multiple explanations are proposed for the slightly lower cecal intubation rate in this population 
compared with that in healthy subjects. The presence of ascites may lead to more mobile bowel loops floating in ascitic fluid and may lower the efficacy of external abdominal pressure to reduce loop formation. ${ }^{(39)}$ In addition, the cecal intubation rate may be adversely affected by other factors, including overall poor general condition and reduced possibilities for effective use of premedication. ${ }^{(39)}$ In the present study, MELD score was identified as an independent predictor for cecal intubation failure, which may support these hypotheses.

Currently, the American Association for the Study of the Liver clinical practice guideline recommends that liver transplantation candidates should undergo an age and risk factor-appropriate cancer screening, including colonoscopy without further specifications. ${ }^{(2)}$ The European Association for the Study of the Liver clinical practice guideline states that CRC screening is mandatory for candidates older than 50 years. ${ }^{(3)}$ However, in light of the currently available data, the indication for standard pre-liver transplantation screening colonoscopy may be questioned, considering the balance between yield and associated risks and costs and considering other important factors such as the substantial waiting list and perioperative mortality.

We suggest that other screening strategies should be considered. A possible alternative approach could be the use of a FIT as a general first-line screening test in subjects aged 50 years or older and consideration of colonoscopy only in patients who have positive FIT results. Patients with IBD, primary sclerosing cholangitis, or other conditions associated with an increased risk for CRC should be managed according to generally accepted guidelines.

This study systematically assessed the complication risk of pre-liver transplantation screening colonoscopy, taking into account the underlying general risk for unwanted events associated with liver disease. The considerable size of the study population and the completeness of data are other factors likely contributing to the reliability of our results. A limitation is that patients who underwent colonoscopy in another center before referral were not taken into account. However, this was a relatively small group, and our study design reflects the real-world situation in a referral hospital for liver transplantation. In addition, because of the retrospective design of the study, not all relevant factors, such as adequacy of bowel preparation, could be fully analyzed.

Future research projects regarding CRC screening in transplant candidates could focus on the assessment of factors relevant for more refined risk stratification in this population, such as age, sex, cause of liver disease, family history of CRC, body mass index, smoking and drinking habits, and comorbidities such as diabetes. It may be equally important to prospectively assess the results of alternative screening strategies.

In conclusion, this study describes the yield and safety of colonoscopy in patients evaluated for liver transplantation screening and provides arguments for why a reconsideration of guidelines regarding the necessity of colonoscopy in unselected patients seems appropriate. We propose that alternative colorectal screening strategies should be considered and further explored.

\section{REFERENCES}

1) Nederlandse Transplantatie Vereniging. Protocol Indicatiestelling en Selectie Voor Levertransplantatie. Haarlem, the Netherlands: Landelijk Overleg Levertransplantatie; 2011.

2) Martin $P$, DiMartini A, Feng S, Brown R Jr., Fallon $M$. Evaluation for liver transplantation in adults: 2013 practice guideline by the American Association for the Study of Liver Diseases and the American Society of Transplantation. Hepatology 2014;59:1144-1165.

3) European Association for the Study of the Liver. EASL Clinical Practice Guidelines: liver transplantation. J Hepatol 2016;64:433-485.

4) Weller DA, DeGuide JJ, Riegler JL. Utility of endoscopic evaluations in liver transplant candidates. Am J Gastroenterol 1998;93:1346-1350.

5) Ishikawa S, Kato J, Kuriyama M, Takemoto K, Uraoka T, Takaki A, et al. Feasibility and findings of colonoscopy for living-donor liver transplant candidates. J Clin Gastroenterol 2009;43:69-74.

6) Weismuller TJ, Bleich F, Negm AA, Schneider A, Lankisch TO, Manns MP, et al. Screening colonoscopy in liver transplant candidates: risks and findings. Clin Transplant 2013;27:E161-E168.

7) Lee HS, Yoo DJ, Park HW, Yang DH, Myung SJ, Yang SK, et al. Is a stricter colonoscopy screening protocol necessary in liver transplant recipients? Comparison with an average-risk population. Dis Colon Rectum 2014;57:976-982.

8) Jeschek P, Ferlitsch A, Salzl P, Heinze G, Gyori G, Reinhart K, et al. A greater proportion of liver transplant candidates have colorectal neoplasia than in the healthy screening population. Clin Gastroenterol Hepatol 2015;13:956-962.

9) Sint Nicolaas J, de Jonge V, Steyerberg EW, Kuipers EJ, van Leerdam ME, Veldhuyzen-van Zanten SJ. Risk of colorectal carcinoma in post-liver transplant patients: a systematic review and meta-analysis. Am J Transplant 2010;10:868-876.

10) Jeon JW, Shin HP, Lee JI, Joo KR, Pack KM, Cha JM, et al. The risk of postpolypectomy bleeding during colonoscopy in patients with early liver cirrhosis. Surg Endosc 2012;26:3258-3263. 
11) Simon K, Orlowska I, Pazgan-Simon M. The risk of complications of endoscopic procedures in patients with liver cirrhosis. Clin Exp Hepatol 2017;3:135-140.

12) Azzam I, Kovalev $Y$, Storch $S$, Elias N. Life threatening hyperphosphataemia after administration of sodium phosphate in preparation for colonoscopy. Postgrad Med J 2004;80:487-488.

13) Boryczka G, Hartleb M, Gutkowski K. Ocena endoskopowa jelita grubego oraz bezpieczenstwo przygotowania jelita i sedoanalgezji u chorych z zaawansowana marskoscia watroby [Endoscopic assessment of large bowel and safety of bowel preparation and sedoanalgesia in patients with advanced liver cirrhosis]. Przegl Lek 2011;68:348-353.

14) Shrake PD, Troiano F, Rex DK. Peritonitis following colonoscopy in a cirrhotic with ascites. Am J Gastroenterol 1989;84:453-454.

15) Christ AD, Bauerfeind P, Gyr N. Peritonitis after colonoscopy in a patient with ascites. Endoscopy 1993;25:553-554.

16) Thornton JR, Losowsky MS. Septicaemia after colonoscopy in patients with cirrhosis. Gut 1991;32:450-451.

17) Welch M, Durrans D. Septicaemia after colonoscopy in patients with cirrhosis. Gut 1992;33:718.

18) Llach J, Elizalde JI, Bordas JM, Gines A, Almela M, Sans M, et al. Prospective assessment of the risk of bacteremia in cirrhotic patients undergoing lower intestinal endoscopy. Gastrointest Endosc 1999;49:214-217.

19) Wai CT. Clinical vigilance is as important as prophylactic antibiotics in patients with cirrhosis who undergo GI endoscopy. Gastrointest Endosc 2004;60:671-672; author reply 672.

20) Child CG, Turcotte JG. Surgery and portal hypertension. Major Probl Clin Surg 1964;1:1-85.

21) Kamath PS, Wiesner RH, Malinchoc M, Kremers W, Therneau TM, Kosberg CL, et al. A model to predict survival in patients with end-stage liver disease. Нepatology 2001;33:464-470.

22) Wiesner R, Edwards E, Freeman R, Harper A, Kim R, Kamath $\mathrm{P}$, et al. Model for end-stage liver disease (MELD) and allocation of donor livers. Gastroenterology 2003;124:91-96.

23) Aronchick CA, Lipshutz WH, Wright SH, DuFrayne F, Bergman G. Validation of an instrument to assess colon cleansing [abstract]. Am J Gastroenterol 1999;94:2667.

24) Aronchick CA, Lipshutz WH, Wright SH, Dufrayne F, Bergman G. A novel tableted purgative for colonoscopic preparation: efficacy and safety comparisons with Colyte and Fleet Phospho-Soda. Gastrointest Endosc 2000;52:346-352.

25) Brahmania M, Park J, Svarta S, Tong J, Kwok R, Enns R. Incomplete colonoscopy: maximizing completion rates of gastroenterologists. Can J Gastroenterol 2012;26:589-592.

26) Bosman FT, Carneiro F, Hruban RH, Theise ND, eds. WHO Classification of Tumours of the Digestive System. 4th ed. Lyon, France: IARC Press; 2010.

27) Hazewinkel Y, de Wijkerslooth TR, Stoop EM, Bossuyt PM, Biermann K, van de Vijver MJ, et al. Prevalence of serrated polyps and association with synchronous advanced neoplasia in screening colonoscopy. Endoscopy 2014;46:219-224.

28) Winawer SJ, Zauber AG. The advanced adenoma as the primary target of screening. Gastrointest Endosc Clin N Am 2002;12:1-9, v.

29) Edge SB, Compton CC. The American Joint Committee on Cancer: the 7th edition of the AJCC cancer staging manual and the future of TNM. Ann Surg Oncol 2010;17:1471-1474.
30) Piano S, Romano A, Di Pascoli M, Angeli P. Why and how to measure renal function in patients with liver disease. Liver Int 2017;37(Suppl 1):116-122.

31) Piano $S$, Tonon $M$, Angeli P. Management of ascites and hepatorenal syndrome. Hepatol Int 2018;12(Suppl 1):122-134.

32) Manning-Dimmitt LL, Dimmitt SG, Wilson GR. Diagnosis of gastrointestinal bleeding in adults. Am Fam Physician 2005;71:1339-1346.

33) Patidar KR, Bajaj JS. Covert and overt hepatic encephalopathy: diagnosis and management. Clin Gastroenterol Hepatol 2015; 13:2048-2061.

34) American Association for the Study of Liver Diseases; European Association for the Study of the Liver. Hepatic encephalopathy in chronic liver disease: 2014 practice guideline by the European Association for the Study of the Liver and the American Association for the Study of Liver Diseases. J Hepatol 2014;61:642-659.

35) Horan TC, Andrus M, Dudeck MA. CDC/NHSN surveillance definition of health care-associated infection and criteria for specific types of infections in the acute care setting. Am J Infect Control 2008;36:309-332.

36) Garner JS, Jarvis WR, Emori TG, Horan TC, Hughes JM. CDC definitions for nosocomial infections, 1988. Am J Infect Control 1988;16:128-140.

37) Warrell DA, Cox TM, Firth JD, eds. Oxford Textbook of Medicine. 4th ed. Oxford, United Kingdom: Oxford University Press; 2010.

38) European Association for the Study of the Liver. EASL clinical practice guidelines on the management of ascites, spontaneous bacterial peritonitis, and hepatorenal syndrome in cirrhosis. J Hepatol 2010;53:397-417.

39) Macken EJ, Steinhauser A, De Schepper HU, De Winter BY, Moreels TG. Colonoscopy in patients with liver cirrhosis: success and safety issues. Acta Gastroenterol Belg 2015;78:411-414.

40) Imperiale TF, Wagner DR, Lin CY, Larkin GN, Rogge JD, Ransohoff DF. Risk of advanced proximal neoplasms in asymptomatic adults according to the distal colorectal findings. N Engl J Med 2000;343:169-174.

41) Stoop EM, de Haan MC, de Wijkerslooth TR, Bossuyt PM, van Ballegooijen M, Nio CY, et al. Participation and yield of colonoscopy versus non-cathartic CT colonography in population-based screening for colorectal cancer: a randomised controlled trial. Lancet Oncol 2012;13:55-64.

42) Alferink LJM, Oey RC, Hansen BE, Polak WG, van Buuren HR, de Man RA, et al. The impact of infections on delisting patients from the liver transplantation waiting list. Transpl Int 2017;30:807-816.

43) Granberry MC, White LM, Gardner SF. Exacerbation of congestive heart failure after administration of polyethylene glycol-electrolyte lavage solution. Ann Pharmacother 1995;29: 1232-1235.

\section{Supporting Information}

Additional Supporting Information may be found at onlinelibrary.wiley.com/doi/10.1002/hep.30562/suppinfo. 